\title{
PERFORMANCE OF SCC WITH PARTIAL REPLACEMENT OF INGREDIENTS OF CONVENTIONAL CONCRETE BY SLAG
}

\author{
M. Mandal, Research Scholar, Civil Engineering Department, Assam Engineering College, Assam, \\ India
}

A. Deka, Assistant Professor, Civil Engineering Department, Jorhat Engineering College, Assam, India U. K. Nath, Professor, Civil Engineering Department, Assam Engineering College, Assam, India

\section{Abstract}

In the present world concrete is not just a construction material consisting of cement, aggregate, and water, but it is an engineered custom-tailored material with several new constituents to meet the specific needs of construction industry. Self-consolidating concrete or self-compaction concrete is the most sought out technology in the concrete industry. It is a highly flowable type of concrete that spreads into the form without the need for mechanical vibration. The importance of selfcompacting concrete is that maintains all concrete's durability and characteristics, meeting expected performance requirements.

Slag is a byproduct of steel production and is similar in character to volcanic rocks such as basalt and granite. Slag is primarily used in the cement and construction industries, and largely in road construction. It is a stony waste matter separated from metals during smelting or refining of ore, and one such constituent which can maximize economic and environmental benefit. Several experiments have proved that it can be used as an effective natural aggregate having a long-term effect on sustainability.

In this research SCC and conventional concrete specimens with varying proportion of slag aggregates were tested for the compressive strengths. The mix design is prepared as per Indian Standard code, IS 10262-2019 with varying water cement ratios to find the optimum percentage to replace the fine aggregates with slag. Three specimens of each mix design were tested for 3-, 7 and 28-days strength and their results noted.

The results show that increase in slag content increases the strength of concrete considerably and however significant results can be obtained by using $50 \%$ replacement of fine aggregates by slag. Thus, it is observed that concrete can be used to recycle slag in many ways.

Keywords: Slag, self-compacting concrete, flow

\section{INTRODUCTION}

Concrete is one of earths largest consumed commodity and self-compacting concrete (SCC) has proved to be a key research direction in the high-performance concrete industry. Selfcompacting concrete is a highly flow-able concrete that can readily spread and fill the formwork without any need for additional compaction. The mixture undergoes no segregation and has significantly reduced bleeding. SCC was first developed to resolve the 
issues of poor concrete placement in heavily reinforced buildings where achieving proper consolidation was a major difficulty. The first generation of SCC had specific applications. Now-a-days SCC is used like standard concrete but with the ability to easily flow through obstructions and corners. It is preferred for closely set formworks as it does not require vibration on tamping after pouring. Self-compacting concrete (SCC) is highly flowable, nonsegregating concrete that fills uniformly and completely every corner of formwork by its own weight and encapsulate reinforcement without any vibration, while maintaining homogeneity. The necessity of this type of concrete was proposed by Prof. Hajimeokamurain (1986). Studies to develop self-compacting concrete, including a fundamental study on the workability of concrete, have been carried out by Ozawa and Maekawaatthe University of Tokyo.

Self-compacting concrete (SCC) was first developed in Japan in the late 1980's as a concrete that can flow through congested reinforcing bars with elimination of compaction, and without undergoing any significant segregation and bleeding (Melo K.A et al., 2010; Siddique R 2011; Liu M 2010). A high slump is needed for such revolutionary concrete, which can be accomplished by adding a superplasticizer. To avoid segregation on super plasticizer addition, the sand content is increased by $4 \%$ to $5 \%$. When the volume of coarse aggregate in the concrete is excessive, the opportunity of contact between coarse aggregate particles increases greatly, causing interlocking and the possibility of blockage on passing through spaces between steel bars is also increased. As a result, the first consideration when constructing SCC is to limit the amount of coarse aggregate. This reduction necessitates the use of more cement, which raises the cost while also causing an unwanted temperature spike. So, cement should be replaced by other mineral admixtures like Blast Furnace Slag, Fly Ash, Silica Fumes, etc. The usage of mineral admixtures in the production of SCC not only provides economic benefits but also reduces heat of hydration (EFNARC guidelines 2002). It is also known that some mineral admixtures may improve rheological properties and reduce thermally induced cracking of concrete due to the reduction in the overall heat of hydration and increase the workability and long-term properties of concrete (Recommendation for Construction of Self Compacting Concrete 1998). There is no standardized mix proportion for designing SCC, hence in this work the Nan Su et al. [Nan Su et al. 2001) method of mix design is adopted with Ground Granulated Blast Furnace Slag (GGBS) and Silica fumes (SF) as powders for partial replacement of cement.

The method for achieving self-compatibility involves not only high deformability of paste or mortar, but also resistance to segregation between coarse aggregate and mortar when the concrete flows through the confined zone of reinforcing bars. The methods to achieve selfcompatibility are: -

(a) Limited aggregate content

(b) Low water-powder ratio 
(c) Use of super plasticizer

When the relative distance between aggregate particles decreases, the probability of collision and interaction between aggregate particles increases, and internal stress increases when concrete is deformed, particularly near obstacles. Research has found that the energy required for flowing is consumed by the increased internal stress, resulting in blockage of aggregate particles. Limiting the coarse aggregate content, whose energy consumption is particularly intense, to a level lower than normal is effective in avoiding this kind of blockage. Highly viscous paste is also required to avoid the blockage of coarse aggregate when concrete flows through obstacles. When concrete is deformed, paste with a high viscosity also prevents localized increases in internal stress due to the approach of coarse aggregate particles. High deformability can be achieved only by the employment of a superplasticizer, keeping the water-powder ratio to a very low value. The degree of packing of coarse aggregate in SCC is approximately $50 \%$ to reduce the interaction between coarse aggregate particles when the concrete deforms. The degree of packing of fine aggregate in SCC mortar is approximately $60 \%$ so that shear deformability when the concrete deforms may be limited. On the other hand, the viscosity of the paste in SCC is the highest among the various types of concrete due to its lowest water-powder ratio. This characteristic is effective in inhibiting segregation.

\section{TYPES OF SLAG}

Different types of slags are used in construction purpose. They are steel slag, air-cooled blast furnace slag, expanded or foamed blast furnace slag, pelletized blast furnace slag, granulated blast furnace slag

\section{MATERIAL PROPERTIES FOR EXPERIMENTATIONS}

\section{Physical Properties}

Steel slag aggregates are highly angular in shape and have rough surface texture. They have high bulk specific gravity and moderate water absorption (less than 3 percent). Table 1 lists some typical physical properties of steel slag.

Table 1: Physical Properties

\begin{tabular}{|c|c|}
\hline Property & Value \\
\hline Specific Gravity $>$ & $3.2-3.6$ \\
\hline Unit Weight, $\mathrm{kg} / \mathrm{m}^{3}\left(\mathrm{lb} / \mathrm{ft}^{3}\right)$ & $1600-1920(100-120)$ \\
\hline Absorption & up to 3\% \\
\hline
\end{tabular}




\section{Chemical Properties}

The chemical composition of slag is usually expressed in terms of simple oxides calculated from elemental analysis determined by $x$-ray fluorescence. Virtually all steel slags fall within these chemical ranges but not all steel slags are suitable as aggregates. Of more importance is the mineralogical form of the slag, which is highly dependent on the rate of slag cooling in the steel-making process. The typical chemical properties of steel slag are tabulated in table 2.

Table 2 Typical steel slag chemical composition

\begin{tabular}{|c|c|}
\hline Constituent & Composition (\%) \\
\hline $\mathrm{CaO}$ & $40-52$ \\
\hline $\mathrm{SiO}_{2}$ & $10-19$ \\
\hline $\mathrm{FeO}$ & $10-40\left(70-80 \% \mathrm{FeO}, 20-30 \% \mathrm{Fe}_{2} \mathrm{O}_{3}\right)$ \\
\hline $\mathrm{MnO}$ & $5-8$ \\
\hline $\mathrm{MgO}$ & $5-10$ \\
\hline $\mathrm{Al}_{2} \mathrm{O}_{3}$ & $1-3$ \\
\hline $\mathrm{P}_{2} \mathrm{O}_{5}$ & $0.5-1$ \\
\hline $\mathrm{S}$ & $<0.1$ \\
\hline Metallic Fe & $0.5-10$ \\
\hline
\end{tabular}

The cooling rate of steel slag is sufficiently low so that crystalline compounds are generally formed. The predominant compounds are dicalcium silicate, tricalcium silicate, dicalcium ferrite, merwinite, calcium aluminate, calcium-magnesium iron oxide, and some free lime and free magnesia (periclase). The relative proportions of these compounds depend on the steel-making practice and the steel slag cooling rate.

Steel slag is slightly alkaline, with a $\mathrm{pH}$ in solution ranging from 8 to 10 . The $\mathrm{pH}$ of steel slag leachate, on the other hand, will reach 11 , and is corrosive to aluminum or galvanized steel pipes in close contact with the slag.

\section{Mechanical Properties}

Processed steel slag has favorable mechanical properties for aggregate use, including good abrasion resistance, good soundness characteristics, and high bearing strength.

Table 3 Typical mechanical properties of steel slag

\begin{tabular}{|c|c|}
\hline Property & Value \\
\hline Los Angeles Abrasion (ASTM C131), \% & $20-25$ \\
\hline Sodium Sulfate Soundness Loss (ASTM C88), \% & $<12$ \\
\hline Angle of Internal Friction & $40^{\circ}-50^{\circ}$ \\
\hline \multicolumn{2}{|c|}{$6-7$} \\
\hline Hardness (measured by Moh's scale of mineral hardness) & up to 300 \\
\hline California Bearing Ratio (CBR), \% top size 19 mm (3/4 inch) ** & Hardness of dolomite measured on same scale is 3 to 4. \\
\hline$*$ Typical CBR value for crushed limestone is 100\%. \\
\hline
\end{tabular}




\section{Thermal Properties}

Due to their high heat capacity, steel slag aggregates have been observed to retain heat considerably longer than conventional natural aggregates. The heat retention characteristics of steel slag aggregates can be advantageous in hot mix asphalt repair work in cold weather.

\section{LITERATURE REVIEW}

Bertil Persson (2001) performed an experimental and numerical analysis on mechanical properties of self-compacting concrete and the related properties of regular compacting concrete, such as strength, elastic modulus, creep, and shrinkage.

Nan Su et al. (2001) suggested a new self-compacting concrete mix construction process. The amount of aggregates, binders, and mixing water, as well as type and dosage of super plasticizer to be used are the major factors influencing the properties of SCC.

Bouzoubaa and Lachemi (2001) performed an experiment to test the efficiency of SCC made with a significant amount of fly ash. During the research, nine SCC mixtures and one control concrete were made. The cementation materials' content was kept stable $(400 \mathrm{~kg} / \mathrm{m} 3)$, while the water/cementation materials ratios varied between 0.35 and 0.45 . Both mixtures were tested to assess the properties of fresh concrete in terms of viscosity and stability

Sri Ravindra Rajah (2003) et al attempted to improve the consistency (cohesiveness) of fresh concrete by increasing the amount of fine materials in the blend. They addressed the development of self-compacting concrete with a lower propensity for segregation.

Hajime Okamura and Masahiro Ouchi (2003) addressed the two major issues faced by the international community in using SCC, namely the absence of a proper mix design method and jovial testing method.

Girishet al (2010) presented the results of an experimental investigation carried out to find out the influence of paste and powder content on self-compacting concrete mixtures.

Cristian Druta (2003) carried out an experimental study on to compare the Splitting Tensile Strength and Compressive Strength values of self-compacting and normal concrete specimens and to examine the bonding between the coarse aggregate and the cement paste using the Scanning Electron Microscope. An average increase in compressive strength of $60 \%$ has been obtained for SCC, whereas $30 \%$ was the increase in splitting tensile strength. Also, due to the use of chemical and mineral admixtures, self-compacting concrete has shown smaller interface micro cracks than normal concrete, fact which led to a better bonding between aggregate and cement paste and to an increase in splitting tensile and compressive strengths. A measure of the better bonding was the greater percentage of the fractured aggregate in SCC (20-25\%) compared to the $10 \%$ for normal concrete.

Surabhi.C.S, Mini Soman, SyamPrakash.V Carried out an experimental study on cement content in the SCC mix is replaced with various percentage of limestone powder and the fresh and hardened properties were studied. It is observed that limestone powder can be 
effectively used as a mineral additive in SCC. Then conclude that result the 7 day and 28-day compressive strength increases with increase in content of limestone powder up to $20 \%$.

$\mathbf{N}$. Bouzouba and $\mathbf{M}$. Lachemi carried out an experimental study on producing and evaluating SCC made with high volumes of fly ash is presented. The high-volume fly ash selfcompacting concretes (except one) have a slump flow in the range of 500 to $700 \mathrm{~mm}$, a flow time ranging from 3 to 7 seconds, a segregation index ranging from 1.9 to $14 \%$, and bleed water ranging from 0.025 to $0.129 \mathrm{~mL} / \mathrm{cm}^{2}$.

Subramanian and Chattopadhyay (2002) described the results of trails carried out to arrive at an approximate mix proportioning of Self compacting concrete. Self-compatibility was achieved for Water to Powder ratio ranging from 0.9 to 1.1 when Coarse Aggregate and Sand content were restricted to $46 \%$ and $40 \%$ of the mortar volume respectively.

Felekoglu (2005) found that the optimum w/c ratio for producing SCC is in the range of 0.84-1.07 by volume. The ratio above and below this range may cause blocking or segregation of the mixture thereby rendering the SCC unusable.

Paratibha Aggarwal (2008) performed experimental investigation and presented a procedure for the design of self-compacting concrete mixes; Slump flow test, $V$-funnel test and L-box test results were found to be satisfactory at the water/powder ratio of 1.180 to 1.215 .

Sheen et al. (2015) tested three different paste contents with water content varying from $175 \mathrm{l} / \mathrm{m}^{3}$ to $210 \mathrm{l} / \mathrm{m}^{3}$ were tested. Slump flow, $\mathrm{V}$ funnel and J-ring tests were carried out to examine the performance of SCC by partially substituting fine and coarse aggregates by oxidizing slag and partial substitution of cement by reducing slag. Results showed that the stainless-steel slag-based SCC can accelerate the hardening process, the compressive strength of SCC prepared with oxidized slag replacement in full exhibits slightly better or at least similar results to that of the control while potentially volumetric instability.

\section{MATERIALS USED}

The material used in the laboratory for investigation the work as follows.

(1) Cement

(2) Fly Ash

(3) Fine Aggregate (Sand)

(4) Coarse Aggregate

(5) Slag Aggregate

(6) Admixtures

(7) Water

The iron slag used in this study is shown in figure 1. 


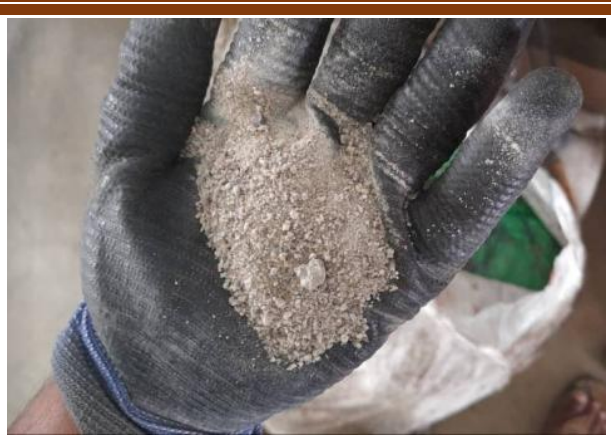

Fig 1Iron Slag

\section{METHODOLOGY}

The methodology adopted during the preparation as well of computation of compressive strength of the mix design carried out are as follows:

- Sieve analysis of fine aggregate was done. Batching and gradation of coarse aggregate was done to meet the desired requirements.

- The general dimensions of the concrete mould that was used in preparation of the cubes is: $(150 \times 150 \times 150) \mathrm{mm}$.

- The experiment was carried out in atmospheric conditions.

- The experiment was carried out in the Concrete Laboratory of Assam Engineering College.

- The moulds were coated with grease so as to allow free movement of concrete paste as well as removal of the cube after it had been casted and setting time was achieved.

- Different grades of concrete is prepared and tested the normal concrete. With the same prportion, concrete is prepared by replacing the fine aggregates with slag aggregates.

\section{TESTS DESCRIPTION FOR SCC}

(As per Indian Standard: Fresh concrete -Methods of sampling, testing and analysisIS 1199(part 6):2018).

A concrete mix can only be classified as self-compacting concrete, if the requirements for all below mentioned characteristics are fulfilled: -

1. Filling ability (Flowability).

2. Passing ability.

3. Segregation resistance.

4. Viscosity.

The mix proportions of concretes are calculated and tabulated in table 4 . Now replacing the fine aggregates with slag in proportions of $40 \%, 50 \%$ and $60 \%$ and tabulated in table 5 
DOI : https://dx.doi.org/10.26808/rs.ed.i11v3.03

International Journal of Emerging Trends in Engineering and Development

Issue 11, Vol.3 (April- May 2021)

Available online on http://www.rspublication.com/ijeted/ijeted_index.htm

ISSN 2249-6149

Table 4Quantity and ratio of materials

\begin{tabular}{|l|c|c|c|c|c|}
\hline & Cementitious (kg) & Water(liters) & FA (kg) & CA(kg) & w/c Ratio \\
\hline Quantity of material & 442 & 190 & 1438 & 97 & 0.43 \\
\hline Ratio of material & 1 & 0.43 & 3.25 & 0.22 & 0.43 \\
\hline $\begin{array}{l}\text { Materials required } \\
\text { for } 1 \text { bag of cement. }\end{array}$ & 50 & 27.2 & 162.5 & 11 & 0.43 \\
\hline
\end{tabular}

Table 5Fine aggregates replacing with slag aggregates

\begin{tabular}{|c|c|c|}
\hline Percentage of replacement & Fine aggregates (sand) & Iron slag aggregates \\
\hline 0 & 1433 & 0 \\
\hline 40 & 860 & 573 \\
\hline 50 & 716.5 & 716.5 \\
\hline 60 & 573 & 860 \\
\hline
\end{tabular}

Trial mix ratios for design mixes M30, M35 and M40 are tabulated in table 6.

Table 6Trial mixes of M30, M35 and M40

\begin{tabular}{|c|c|c|c|c|c|c|}
\hline Grade & Items & Cement (kg) & Water (L) & FA(kg) & CA (kg) & w/c Ratio \\
\hline \multirow{3}{*}{ M30 } & Quantity of material & 442 & 190 & 1433 & 111 & 0.43 \\
\hline & Ratio of material & 1 & 0.43 & 3.24 & 0.24 & 0.43 \\
\hline & Materials required for 1 bag of cement. & 50 & 27.2 & 162.5 & 12.6 & 0.43 \\
\hline \multirow{3}{*}{ M35 } & Quantity of material & 487 & 190 & 1433 & 68 & 0.43 \\
\hline & Ratio of material & 1 & 0.43 & 2.94 & 0.14 & 0.43 \\
\hline & Materials required for 1 bag of cement. & 50 & 25.2 & 147.2 & 7 & 0.43 \\
\hline \multirow{3}{*}{ M40 } & Quantity of material & 527 & 190 & 1433 & 29.42 & 0.43 \\
\hline & Ratio of material & 1 & 0.43 & 2.72 & 0.6 & 0.43 \\
\hline & Materials required for 1 bag of cement. & 50 & 18 & 136 & 3 & 0.43 \\
\hline
\end{tabular}

The test results of fresh concrete and hardened concrete of different grades are tabulated in table 7 and 8 respectively. 
Table 7test results of fresh concrete

\begin{tabular}{|l|c|c|c|}
\hline Grade of concrete & M30 & M35 & M40 \\
\hline Mean Target Strength(N/mm2) & $38.25 \mathrm{~N} / \mathrm{mm}^{2}$ & $43.25 \mathrm{~N} / \mathrm{mm}^{2}$ & $48.25 \mathrm{~N} / \mathrm{mm}^{2}$ \\
\hline Water cement ratio & 0.43 & 0.39 & 0.36 \\
\hline Slump flow & $125 \mathrm{~mm}$ & $128 \mathrm{~mm}$ & $119 \mathrm{~mm}$ \\
\hline$t_{500}($ in sec) & $2 \mathrm{sec}$ & $2 \mathrm{sec}$ & $2 \mathrm{sec}$ \\
\hline L Box test (Passing ability) & 0.15 & 0.15 & 0.15 \\
\hline V funnel flow time & $>25 \mathrm{sec}$ & $>25 \mathrm{sec}$ & $>25 \mathrm{sec}$ \\
\hline Segregation Ratio & $>15 \%$ & $>15 \%$ & $>15 \%$ \\
\hline
\end{tabular}

Table 8 test results of hardened concrete

\begin{tabular}{|c|c|c|c|}
\hline \multirow[t]{3}{*}{ Concrete Mix } & \multirow{2}{*}{$\begin{array}{l}\text { Slag replacement in } \\
\text { percentage }\end{array}$} & \multicolumn{2}{|c|}{ Compressive strength } \\
\hline & & at 7 days in $\mathrm{N} / \mathrm{mm}^{2}$ & at 28 days in $\mathrm{N} / \mathrm{mm}^{2}$ \\
\hline & 0 & 22.75 & 38.25 \\
\hline \multirow{3}{*}{ M30 } & 20 & 23.04 & 39.14 \\
\hline & 40 & 24.21 & 40.88 \\
\hline & 60 & 24.94 & 42.12 \\
\hline \multirow{4}{*}{ M 35} & 0 & 23.72 & 44.48 \\
\hline & 20 & 24.14 & 45.26 \\
\hline & 40 & 25.60 & 46.85 \\
\hline & 60 & 25.12 & 45.22 \\
\hline \multirow{4}{*}{ M 40} & 0 & 26.30 & 47.52 \\
\hline & 20 & 26.94 & 47.90 \\
\hline & 40 & 27.48 & 48.54 \\
\hline & 60 & 27.01 & 48.22 \\
\hline
\end{tabular}

The graphical representation of test results at 7 days and 28 days are shown in figure 2 and 3 respectively. 


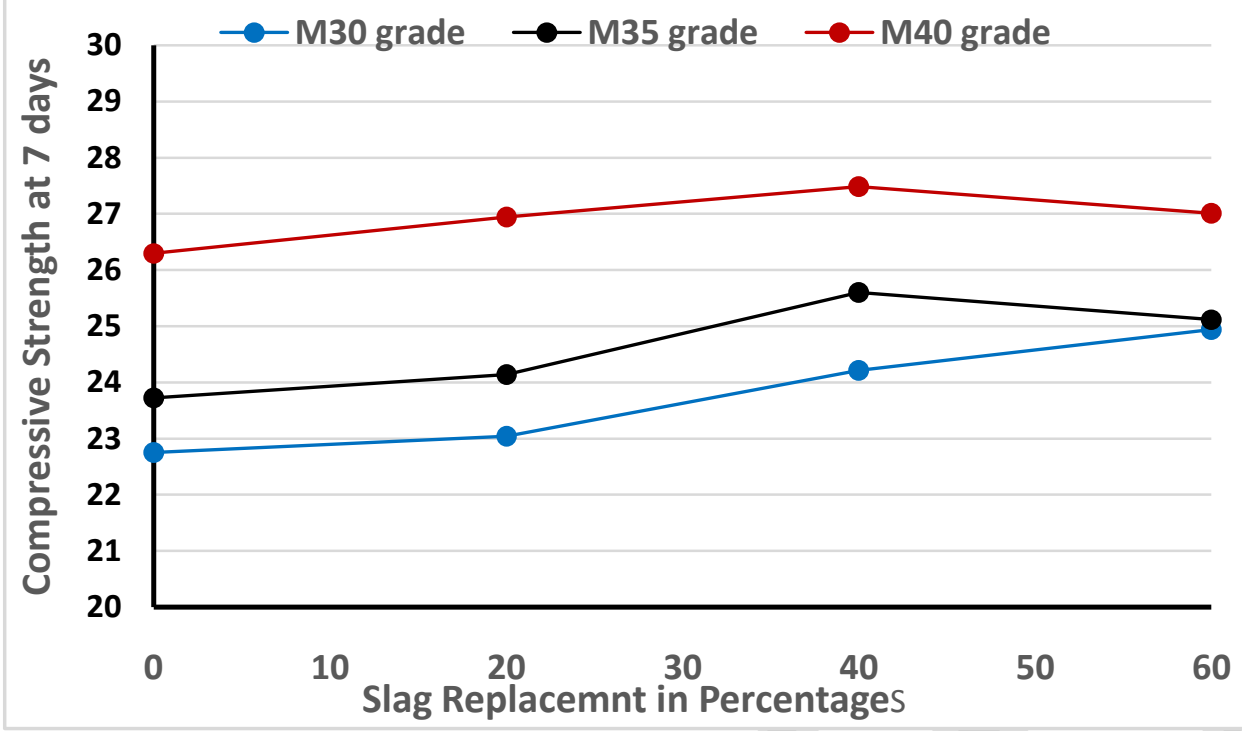

Fig 2Compressive strength of different grade of concrete at 7 days in terms of replacement of slag aggregate (in \%)

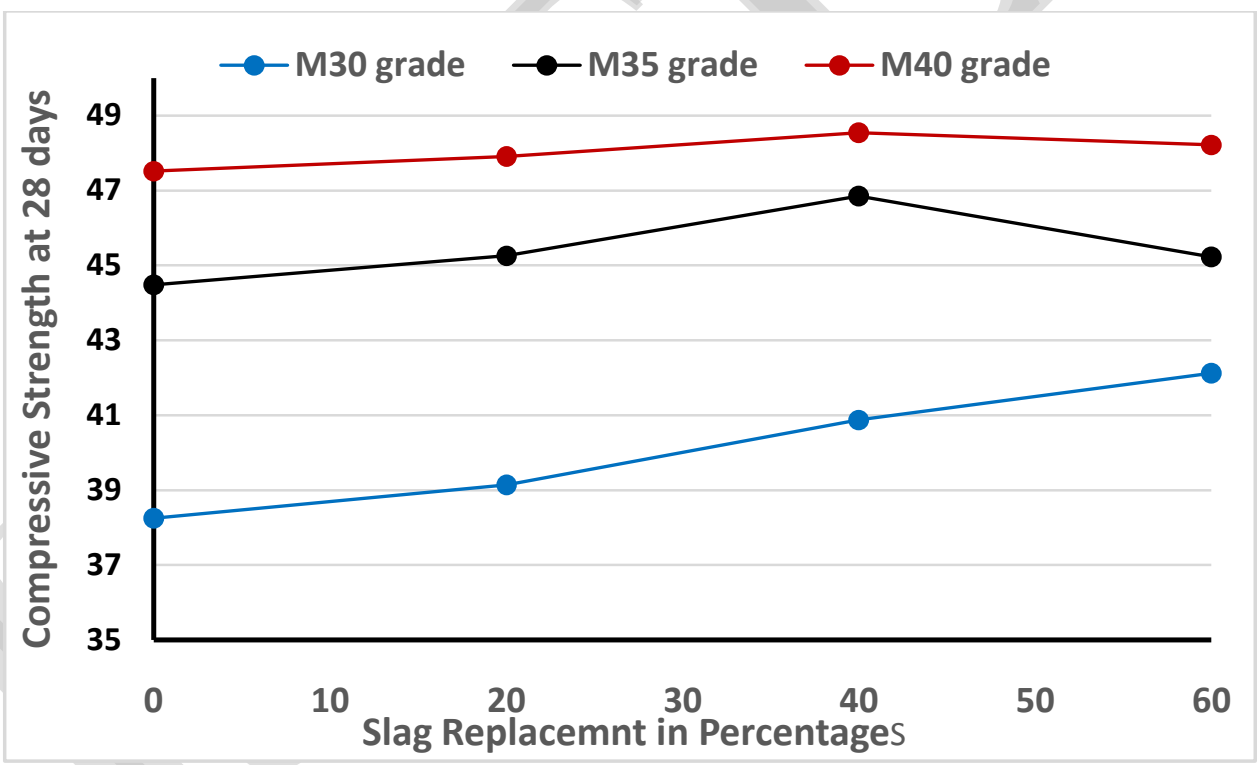

Fig 3Compressive strength of different grade of concrete at 28 days in terms of replacement of slag aggregate (in \%)

The following points can be incurred based on the results of the study:

(1) The results show optimum slag replacement as 40 percent.

(2) The powder content plays a very vital role in the design of the SCC. With the increase of the design mix, the powder content has increased. If it is not increased, it leads to failure of the SCC. The increase in powdered fines ensure flowability of the concrete. 
(3) The powder content is the amount of fines $(<125 \mathrm{~mm})$ which come from the OPC, fly ash and fine aggregates. So, the amount of fines obtained from sieve analysis plays a great role in determining the content of the fine aggregates needed. This percentage of fines obtained from fine aggregates is taken to very high in the code.

(4) Also, the volume of coarse aggregate which directly depends upon the volume of fine aggregate gives negative result as the amount of fine aggregate is increased due to lesser percentage of fines obtained from the sieve analysis of the fine aggregate. Hence the powder content cannot be increased.

(5) The ratio of water to powder by volume should also be in range which is between 0.85 to 1.10 . Increasing water content to increase the cementitious materials to achieve maximum flowability gives the ratio of water to powder out of range.

\section{CONCLUSION}

The self-compacting concrete was obtained adding a special admixture and its flowability was tested using the $V$ funnel test and $L$ box test. This resulted in higher values of compressive strength than the conventional concrete. However, comparatively decrease in strength is observed for the SCC specimens having slag replacement more than $50 \%$. Also due to the presence of admixture, the SCC showed smoother surface with smaller cracks and far better bonding between aggregate and cement paste. The presence of silica fumes in the SCC acted as fillers between the particles of coarse aggregates and fine aggregates.

\section{Acknowledgement}

The study described in this paper was supported by the Collaborative Research Project under TEQIP-III of ASTU. The authors would like to express their sincere thanks to the staff of Civil Department, Assam Engineering College for providing the assistance required for the project.

\section{References}

1) Bertil Persson (2001) A comparison between mechanical properties of self-compacting concrete and the corresponding properties of normal concrete Cement and Concrete Research, 31, pp 193-198.

2) Felekoglu B, Turkel S, Baradan B (2005) Effect of w/c ratio on the fresh and hardened properties of SCC. Building and Environment Research. vol: 35, pp.373-379

3) Girish S, Ranganath RV, Vengala J (2010) Influence of powder and paste on flow properties of SCC. Construction and Building Materials, pp 2481-2488.

4) Hisham Q (2018) Towards sustainable self-compacting concrete: effect of recycled slag coarse Aggregate on the fresh properties of SCC, Advanced Civil Engineering, pp 1-9.

5) Nehdi ML, Pardhan M, Koshowski S (2004) Durability of self-consolidating concrete incorporating high-volume replacement composite cements, Cement and Concrete Research, vol 34, pp.2103-2112 
6) N. Bouzouba and M. Lachemi (2001) Self Compacting Concrete Incorporating High-Volumes of Class Fly AshCement and Concrete Research, Vol. 31, No. 3, pp. 413-420.

7) Paratibha Aggarwal, Aggarwal and Surinder M Gupta (2008) Self-Compacting Concrete Procedure for Mix Design Leonardo Electronic Journal of Practices and Technologies, Issue 12, pp 15-24.

8) S. Girish, R.V. Ranganath and Jagadish Vengala (2010) Influence of powder and paste on flow properties of SCC Onstruction and Building Materials, 24, pp 2481-2488.

9) S Subramanian, S. (1999) Interfaces in concrete - Achieving performance International Conference on Concretes, Dundee, Scotland.

10) Sheen $Y$, Le D, Sun T (2015) Innovative usages of stainless-steel slags in developing selfcompacting concrete, Construction Building Material, vol 101, pp 268-276.

11) Sosa I, Thomas C, Polanco JA, Setién J, Tamayo P (2020) High performance self-compacting concrete with electric arc furnace slag aggregate and cupola slag powder, Applied Science, vol 10, pp 773-779. 